\title{
Absorption of Iodine by Polymers and Electrochemical Response of Polymer Film in Aqueous Solution of Iodine
}

\author{
Hiroshi Sukawa, Yukihiro Yoda, Hirotsugu Sugimoto, \\ Shunji YoshidA, Takakazu Yamamoto, ${ }^{*, \dagger}$ Shinichi KurodA, ${ }^{*}$ \\ Kenichi SANECHIKA, ${ }^{*}$ and Masakazu HiShinUmA ${ }^{* *}$ \\ Research Center, Mitsui Toatsu Chemicals, Inc., 1190 Kasama-cho, \\ Sakae-ku, Yokohama 247, Japan \\ * Research Laboratory of Resources Utilization, Tokyo Institute of Technology, \\ 4259 Nagatsuta, Midori-ku, Yokohama 227, Japan \\ ** Department of Environmental Science, School of Public Health, \\ Harvard University, Boston, MA02115, U.S.A.
}

(Received November 9, 1988)

\begin{abstract}
Isotherms for absorption of iodine by various polymers have been measured at $25^{\circ} \mathrm{C}$ in aqueous media. Poly(3-vinyl-10-methylphenothiazine) (PVMP), poly(4-vinylpyridine), and poly(tetramethylene ether glycol) absorb $3.0 \mathrm{~g}, 2.3 \mathrm{~g}$, and $1.8 \mathrm{~g}$ of iodine, respectively, per $1.0 \mathrm{~g}$ of the polymer when dipped in a $0.05 \mathrm{M}$ aqueous solution of $\mathrm{I}_{2}$ containing $\mathrm{KI}$ at $25^{\circ} \mathrm{C}$. 6-Nylon, poly(vinyl alcohol), poly(acrylonitrile), poly(acrylamide) absorb $1.7 \mathrm{~g}, 1.5 \mathrm{~g}, 1.2 \mathrm{~g}$, and $0.82 \mathrm{~g}$ of iodine, respectively, per $1.0 \mathrm{~g}$ of the polymer when dipped in a $0.10 \mathrm{M}$ aqueous solution of $\mathrm{I}_{2}$ under the same conditions. Except for 6-nylon, the dependence of the amount of absorbed iodine on $\left[\mathrm{I}_{2}\right]$ obeys a Langmuir-type equation obtained assuming the equilibrium, $\mathrm{I}_{2}+$ polymer $\stackrel{K}{\rightleftharpoons} \mathrm{I}_{2}$-polymer complex. The equilibrium constant $K$ ranges from $13 \mathrm{M}^{-1}$ (for poly(vinyl alcohol)) through $53 \mathrm{M}^{-1}$ (for PVMP). Cyclic voltammograms obtained using a polymer electrode coated on a Pt wire show the occurrence of smooth oxidation and reduction of $\mathrm{I}^{-}$and $\mathrm{I}_{2}$, respectively, on the surface of the polymer electrode and inside of the polymer electrode.
\end{abstract}

KEY WORDS Absorption / Iodine / Poly(3-vinyl-10-methylphenothiazine)

/ Polymer Electrode /

It is well known that iodine forms complexes with various polymers including poly(vinyl alcohol), poly(acrylamide), poly(4-vinylpyridine), and nylon-6. ${ }^{1-10}$ However, a systematic study on the absorption equilibrium of iodine by various polymers has not been reported.

Recently, it has been shown that the polymer-iodine complex is useful as an active material of a $\mathrm{Zn}-\mathrm{I}_{2}$ rechargeable battery. ${ }^{11-13}$ In the charging stage of the battery using the polymer electrode and a $\mathrm{ZnI}_{2}$ aqueous solution as the electrolytic solution, molecular iodine formed is absorbed into the polymer-based electrode to form the polymer-iodine complex.

Charging reaction at positive electrode:

$$
\begin{aligned}
& 2 \mathrm{I}^{-} \rightarrow \mathrm{I}_{2}+2 \mathrm{e}^{-} \\
& \mathrm{I}_{2}+\text { polymer } \rightleftharpoons \text { iodine complex } \\
& \quad \text { (active material of the battery) }
\end{aligned}
$$

In the discharging stage, reverse reactions take place.

In order to reveal the role of the polymerbased electrode of the battery, we investigated 1) the absorption equilibrium of iodine by

\footnotetext{
† To whom correspondence should be addressed.
} 
various polymers in aqueous media and 2) electrochemical response of polymer film electrodes in aqueous solutions containing iodine. We now report the results.

\section{EXPERIMENTAL}

Poly(3-vinyl-10-methylphenothiazine) 1 was prepared by the radical polymerization of 3vinyl-10-methylphenothiazine according to the method described in literature. ${ }^{14}$ Poly(4vinylpyridine), nylon-6, poly(vinyl alcohol), poly(acrylonitrile), and poly(acrylamide) were purchased from Polysciences Co., Ltd. Poly(tetramethylene ether glycol) with $\bar{M}_{w}$ of 2900 was produced by Mitsui Toatsu Chemicals Inc.

The polymer (powder) was added to an aqueous solution containing $\mathrm{KI}\left(0.2 \mathrm{moll}^{-1}\right)$ and $\mathrm{I}_{2}$. The solution was thermostated $\left(25^{\circ} \mathrm{C}\right)$. After stirring for $12 \mathrm{~h}$, the polymer-iodine adduct was separated by filtration. Poly(vinyl alcohol) and poly(acrylamide) are soluble in water, but their iodine adducts obtained under the experimental conditions were not soluble in the aqueous solution. The concentration of iodine in the remaining solution was determined by titration with an aqueous solution of $\mathrm{Na}_{2} \mathrm{~S}_{2} \mathrm{O}_{3}$. The amount of iodine absorbed by the polymer was calculated from the difference in the initial concentration of iodine and its final concentration after absorption by the polymer. Iodine was smoothly absorbed by the polymer and equilibrium was attained after $12 \mathrm{~h}$. The concentration of iodine in the aqueous solution after $12 \mathrm{~h}$ was taken as its equilibrated concentration.

Cyclic voltammetry was carried out using a Hokuto-denko potentiostat/galvanostat HA301 and function generator HB-104. A platinum wire $(\phi=0.30 \mathrm{~mm})$ was dipped (length $=$ $1.0 \mathrm{~cm}$ ) into a polymer solution containing dispersed carbon powder $(30 \mathrm{wt} \%$ per the polymer, Ketjen black EC (commercial code of Akzo Co., Ltd.). After taking out the platinum wire from the polymer solution, the polymer on the platinum wire was dried at room temperature under vacuum. The polymer-coated platinum wire thus prepared was used for the cyclic voltammetry.

\section{RESULTS AND DISCUSSION}

\section{Absorption of Iodine}

Figure 1 shows the dependence of the amount of iodine absorbed by the polymer on the concentration of iodine, which mainly existed as $\mathrm{I}_{3}^{-}\left(\mathrm{I}_{2}+\mathrm{I}^{-} \rightleftharpoons \mathrm{I}_{3}{ }^{-}\right)$in the aqueous solution of KI. The amount of iodine absorbed by 6 -nylon at $\left[\mathrm{I}_{2}\right]=0.1 \mathrm{moll}^{-1}$ was comparable to a reported amount obtained using an acetone solution of iodine. ${ }^{12}$

If iodine is absorbed as molecular $\mathrm{I}_{2}$, the number of $\mathrm{I}_{2}$ molecules absorbed by each monomer unit of the polymer is calculated as shown in Figure 2. As shown in Figure 2, poly(acrylonitrile) (PAN), poly(vinyl alcohol) (PVA), poly(acrylamide) (PAM) ab-

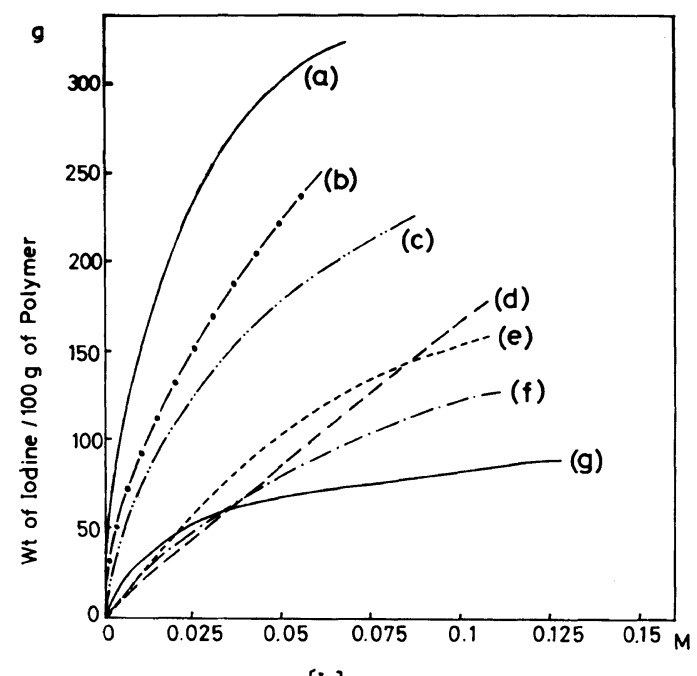

[I 2 ]

Figure 1. Dependence of the amount of iodine absorbed by polymers on the equilibrated concentration of iodine in aqueous solution at $25^{\circ} \mathrm{C}$. Polymer: (a) poly(3vinyl-10-methylphenothiazine) (PVMP); (b) poly(4vinylpyridine) (P4VP); (c) poly(tetramethylene ether glycol) (PTMEG); (d) 6-nylon; (e) poly(vinyl alcohol) (PVA); (f) poly(acrylonitrile) (PAN); (g) poly(acrylamide) (PAM). $[\mathrm{KI}]=0.20 \mathrm{moll}^{-1}$. 


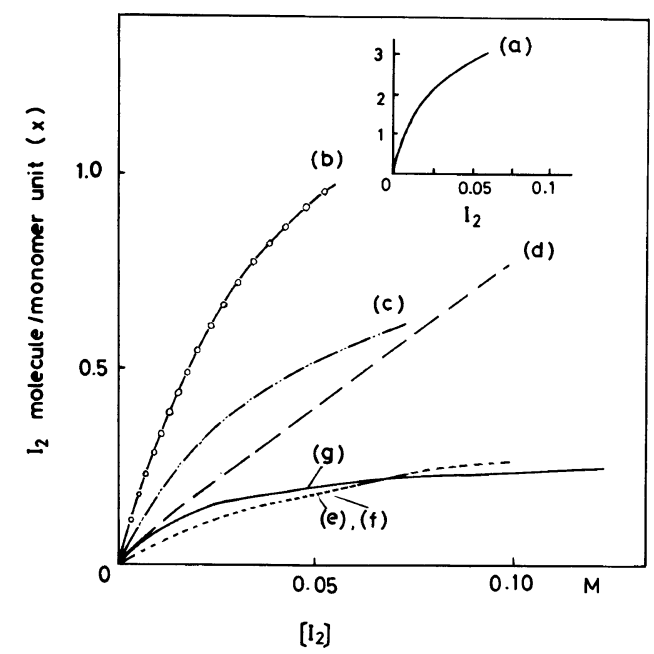

Figure 2. Dependence of the number of $I_{2}$ molecules absorbed by each monomer unit of the polymer. As for (a) - (g), see the caption of Figure 1. Curves (e) and (f) roughly are superimposable on each other.

sorb about 0.25 of $\mathrm{I}_{2}$ per each monomer unit at $\left[I_{2}\right]=0.1 \quad \mathrm{moll}^{-1}$. Poly(4-vinylpyridine) (P4VP), poly(tetramethylene ether glycol) $\left(\mathrm{HO}\left(\left(-\mathrm{CH}_{2}\right)_{4} \mathrm{O}\right)_{n} \mathrm{H}\right.$, PTMEG, $\left(M_{w}=2,900\right)$, and 6-nylon absorb more than $0.5 \mathrm{~mol}$ of $\mathrm{I}_{2}$ per each monomer unit. Poly(3-vinyl-10methylphenothiazine) (PVMP),

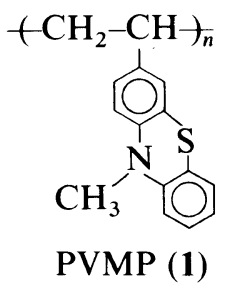

which has both an electron donating nitrogen atom and aromatic ring and therefore considered to have strong electron donating ability, absorbs a very large amount of iodine per the monomer unit.

Assumption of the following equilibrium,

$$
\begin{aligned}
& \text { Absorption site }+\mathrm{I}_{2} \stackrel{K}{\rightleftharpoons} \underset{ }{\rightleftharpoons-X} \\
& \mathrm{I}_{2} \text {-polymer complex } \\
& X
\end{aligned}
$$

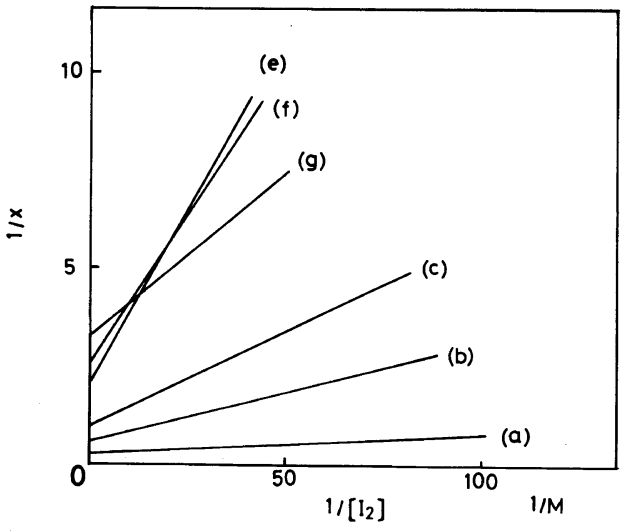

Figure 3. Plot of $1 / x$ against $1 /\left[\mathrm{I}_{2}\right]$. As for (a) - (g), see the captions of Figure 1.

gives

$$
\begin{aligned}
K & =\frac{\left[\mathrm{I}_{2}-\text { polymer complex }\right]}{[\text { Absorption site }]\left[\mathrm{I}_{2}\right]} \\
& =\frac{X}{(A-X)\left[\mathrm{I}_{2}\right]}=\frac{x}{(a-x)\left[\mathrm{I}_{2}\right]}
\end{aligned}
$$

or

$$
\frac{1}{x}=\frac{1}{K a} \cdot \frac{1}{\left[\mathrm{I}_{2}\right]}+\frac{1}{a}
$$

where $A$ and $X$ represent concentrations of the initial absorption site of the polymer and $\mathrm{I}_{2}-$ polymer complex, respectively, and $a$ and $x$ represent the number of the absorption sites per the monomer unit and number of the $\mathrm{I}_{2}-$ polymer complexes formed per the monomer unit, respectively. The absorption of iodine by the polymer as $\mathrm{I}_{3}{ }^{-}$-adduct, which is sometimes proposed, ${ }^{7}$ gives essentially the same equation as eq 5 .

Plot of $1 / x$ in Figure 2 against $1 /\left[I_{2}\right]$ affords a linear line when 1, poly(4-vinylpyridine), poly(tetramethylene ether glycol), poly(vinyl alcohol), poly(acrylonitrile), or poly(acrylamide) is used. In the case of 6-nylon, however, the amount of iodine absorbed increased roughly linearly with increase in $\left[\mathrm{I}_{2}\right]$ as shown in Figures 1 and 2, and consequently the plot of $1 / x$ against $1 /\left[\mathrm{I}_{2}\right]$ considerably deviated from the linear line. This may be 
Table I. Parameters for the formation of the iodine-polymer adduct at $25^{\circ} \mathrm{C}$

\begin{tabular}{lcc}
\hline Polymer & $a$-Value & $K$-Value $\left(\mathrm{mol}^{-1}\right)$ \\
\hline $\begin{array}{c}\text { Poly(3-vinyl-10-methyl- } \\
\text { phenothiazine) (PVMP) }\end{array}$ & $c a .3 .6$ & 53 \\
$\begin{array}{l}\text { Poly(4-vinylpyridine) } \\
\text { (P4VP) }\end{array}$ & 1.8 & 22 \\
$\begin{array}{l}\text { Poly(tetramethylene ether } \\
\text { glycol) (PTMEG) }\end{array}$ & 1.1 & 19 \\
$\begin{array}{l}\text { Poly(acrylonitrile) (PAN) } \\
\text { Poly(vinyl alcohol) (PVA) } \\
\text { Poly(acrylamide) (PAM) }\end{array}$ & 0.5 & 13 \\
\hline
\end{tabular}

due to (a) the large a value in eq 5 with relatively small $K$ value or (b) change of $a$ and $K$ values with increase of the amount of iodine absorbed (e.g., $a$ and $K$ values may increase with the amount of iodine absorbed due to change of chain structure of the iodine-6nylon adduct). The absorption of iodine by 6 nylon in acetone solutions ${ }^{12}$ roughly agrees with eq 5 , and a $K$ value of about $30 \mathrm{lmol}^{-1}$ was estimated from the absorption curve.

Table I summarizes $a$ and $K$ values calculated from the plot shown in Figure 3. As shown in Table I, poly(vinyl alcohol) (PVA), poly(acrylonitrile), and poly(acrylamide) can potentially take $0.4 \pm 0.1 \mathrm{I}_{2}$ per the monomer unit. If, as proposed previously, ${ }^{3,15}$ PVA absorbs iodine as $\mathrm{I}_{5}{ }^{-}$, the results (absorption of $0.5 \mathrm{moll}^{-1}$ of $\mathrm{I}_{2}$ per the monomer unit) indicate that PVA can absorb 0.25 molecule of $\mathrm{I}_{5}{ }^{-}$per monomer unit probably in a helical cage of PVA..$^{3,8,15,16}$

Poly(tetramethylene ether glycol) and poly(4-vinylpyridine) seem to have the potential ability to absorb about one and two $I_{2}$ molecules per monomer unit, respectively. The absorption of a large amount of $\mathrm{I}_{2}$ per the monomer unit of poly(3-vinyl-10-methylphenothiazine) is attributed to presence of two donor centers ( $\mathrm{S}$ and $\mathrm{N}$ ) and aromatic rings. The large amount of $\mathrm{I}_{2}$ absorbed may be attributed to the partial participation of $\mathrm{I}_{5}{ }^{-}$ formed from $\mathrm{I}^{-}$and $\mathrm{I}_{2}$ in the complex formation with PVMP. It is reported that some polymer-iodine complexes contain $\mathrm{I}_{5}{ }^{-}$besides $\mathrm{I}_{3}{ }^{-17}$ The formation constant of the $\mathrm{I}_{2}-$ complexes ranges from 13 through $53 \mathrm{M}^{-1}$ at $25^{\circ} \mathrm{C}$, the value being considerably smaller than the formation constant of $\mathrm{I}_{2}$-complex of amylose $\left(\right.$ ca. $\left.1.0 \times 10^{4} \mathrm{M}^{-1}\right){ }^{7}$

\section{Electrochemical Response of Polymer Electrode in $\mathrm{ZnI}_{2}$ Solution}

Figures $4 \mathrm{a}-\mathrm{c}$ show cyclic voltammograms of polymer electrodes in an aqueous solution of $\mathrm{ZnI}_{2}$. As shown in the figures, the oxidation of $\mathrm{I}^{-}$to $\mathrm{I}_{2}$ starts at $0.3-0.4 \mathrm{~V}$ vs. $\mathrm{Ag} / \mathrm{AgCl}$, which corresponds to the standard oxidation potential of $\mathrm{I}^{-}(0.314 \mathrm{~V}$ vs. $\mathrm{Ag} / \mathrm{AgCl}) .{ }^{18,19} \mathrm{I}_{2}$ (or $\mathrm{I}_{3}{ }^{-}$) thus formed on the surface of the polymer electrode and/or inside of the polymer electrode is absorbed by the polymer electrode (this may be called "doping"), and it is reduced in cathodic scanning and $\mathrm{I}^{-}$thus regenerated is liberated from the polymer electrode ("undoping").

$$
\begin{aligned}
& 2 \mathrm{I}^{-}+\text {polymer } \underset{\text { cathodic scanning }}{\stackrel{\text { anodic scanning }}{\rightleftharpoons}} \\
& \mathrm{I}_{2}-\text { polymer complex }+2 \mathrm{e}^{-}
\end{aligned}
$$

The flow of a large electric current observed for poly(tetramethylene ether glycol) and 6nylon (Figures $4 \mathrm{a}$ and b) electrodes indicates that smooth oxidation of $\mathrm{I}^{-}$and reduction of $I_{2}$, respectively, takes place on the surface of the polymer electrode (and also probably inside the polymer electrode). The change of the cyclic voltammograms with cycle number in early cycles is attributed to the change of state of the polymer electrode in the aqueous solution with time (e.g., increase in the amount of absorbed aqueous solution inside of the polymer electrode). After about 10 cycles, the electrodes give a stable cyclic voltammogram.

Compared with the PTMEG and 6-nylon electrodes, poly(acrylonitrile) electrode (Figure 4c) gives a considerably smaller electric current. The difference in electric current between the PTMEG and 6-nylon electrodes 


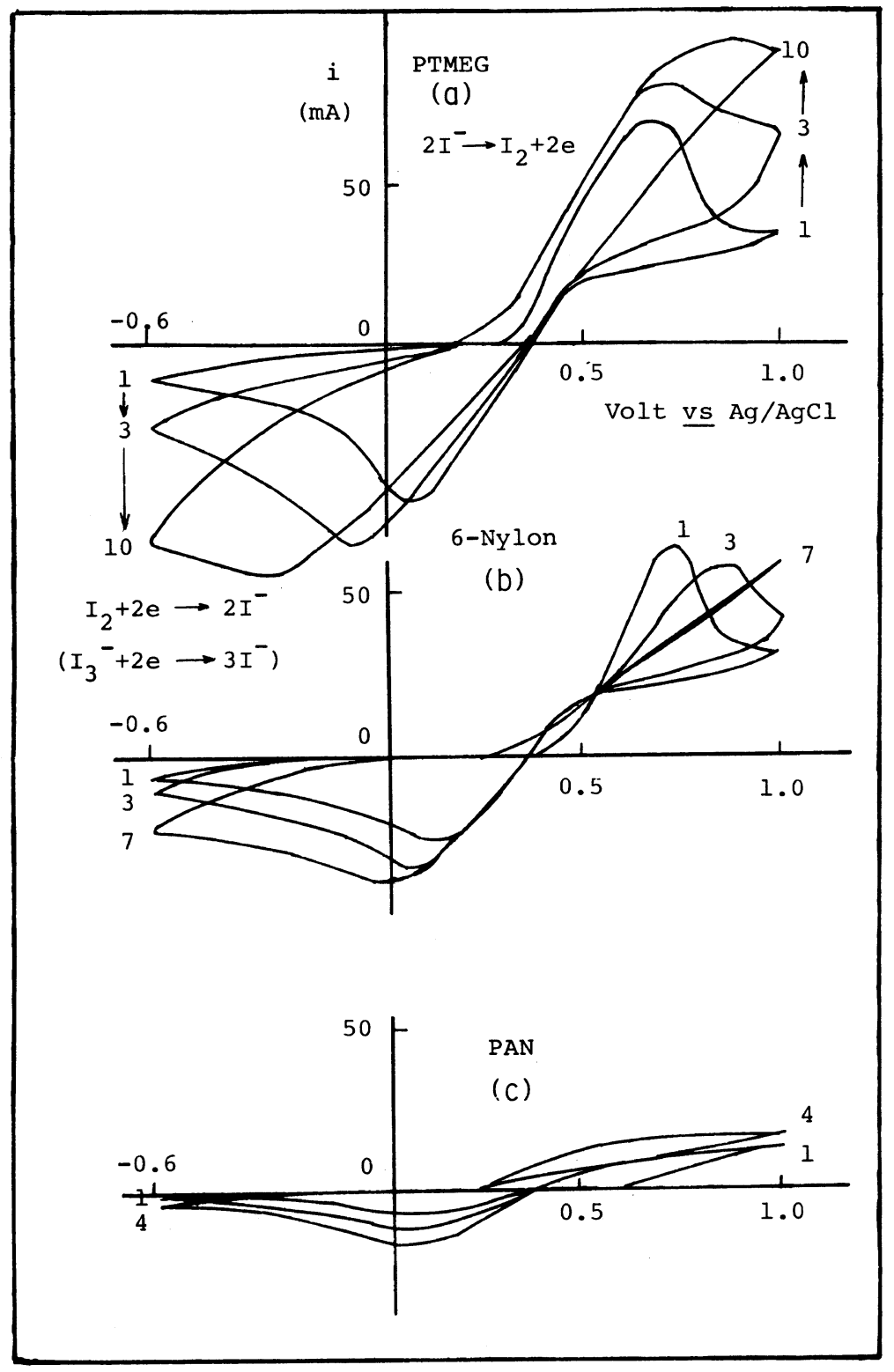

Figure 4. Cyclic voltammograms obtained using polymer electrodes in an aqueous solution containing $1 \mathrm{M}$ of $\mathrm{ZnI}_{2}$ and $2 \mathrm{M}$ of $\mathrm{NH}_{4} \mathrm{Cl}$ at $25^{\circ} \mathrm{C}$. Scanning rate $=100 \mathrm{mV} \mathrm{s}^{-1}$. Polymer: (a) poly(tetramethylene ether glycol); (b) 6-nylon; (c) poly(acrylonitrile). The number indicates the scanning number. After 10th 8 th, and 4 th scannings in Figures $4 a, 4 b$, and $4 c$, respectively, the profile of the cyclic voltammogram did not vary with the number of scannings. In the reaction equation in Figure $4 a, I_{2}$ means the $I_{2}-$ polymer complex. The numbers in the figures are scanning numbers.

and poly(acrylonitrile) electrode seems due to the difference in ease (or rate) of absorption of iodine by the polymers.
Charge-discharge behavior of $\mathrm{Zn}\left|\mathrm{ZnI}_{2}\right| \mathrm{I}_{2}-$ polymer complex secondary cell ${ }^{11-13}$ reflects the difference in the cyclic voltammograms 
observed for the polymers; the secondary cell using PTMEG or 6-nylon electrode gave much better charge-discharge behavior than that using poly(acrylonitrile). Due to strong absorption ability of poly(3-vinyl-10-methylphenothiazine), it served as an excellent electrode for the secondary cell, too. The chargedischarge behavior of the $\mathrm{Zn}\left|\mathrm{ZnI}_{2}\right| \mathrm{I}_{2}$-polymer complex secondary cell using various polymer electrodes will be reported elsewhere.

\section{REFERENCES}

1. F. Z. Cramer, Naturwissenschaften, 38, 188 (1951).

2. R. F. Cournoyer and S. Siggria, J. Polym. Sci., Polym. Chem. Ed., 19, 603 (1966).

3. M. M. Zwick, J. Polym. Sci. A-1, 4, 1642 (1966).

4. A. A. Schneider, D. E. Harney, and M. J. Harney, $J$. Power Sources, 5, 15 (1980).

5. S. B. Mainthia, P. L. Kronick, and M. M. Labes, $J$. Chem. Phys., 41, 2206 (1964).

6. T. Yamamoto, H. Sugimoto, and M. Hishinuma, $J$. Mater. Sci., 21, 604 (1986).

7. M. Yamamoto, T. Sano, and T. Yasunaga, Bull. Chem. Soc. Jpn., 55, 1886 (1982).
8. Y. Oishi and K. Miyasaka, Polym. J., 18, 307 (1986).

9. J. Gacen and J. Maillo, Bull. Sci. Inst. Text. Fr., 11, 9 (1982).

10. H. Arimoto, Kobunshi Kagaku, 19, 101 and 205 (1962).

11. T. Yamamoto, J. Chem. Soc., Chem. Commun., 187 (1981).

12. T. Yamamoto and S. Kuroda, J. Electroanal. Chem., 158, 1 (1983).

13. T. Yamamoto, M. Hishinuma, H. Sugimoto, and A. Yamamoto, J. Electroanal. Chem., 194, 197 (1985).

14. Y. Morishita, Y. Itoh, and A. Koyagi, J. Polym. Sci., Polym. Chem. Ed., 21, 953 (1983).

15. T. Yokota and Y. Kimura, Makromol. Chem., 186, 549 (1985).

16. M. K. Pal and P. K. Pal, Makromol. Chem., 188, 1735 (1987).

17. T. Matsuyama, H. Sakai, H. Yamaoka, Y. Maeda, and H. Shirakawa, Solid State Commun., 40, 563 (1981); G. Kaindl, G. Wortmann, S. Roth, and K. Menke, ibid., 41, 75 (1982); H. Sakai, M. Mizota, Y. Maeda, T. Yamamoto, and A. Yamamoto, Bull. Chem. Soc. Jpn., 58, 926 (1985).

18. W. M. Latimer, "Oxidation Potentials," 2nd ed, Prentice-Hall Inc., New York, 1952.

19. M. Pourbaix, "Atlas of Electrochemical Equilibria in Aqueous Solutions," Pergamon Press, New York, 1966. 